\section{Facultad de Odontología de la Universidad Nacional Mayor de San Marcos: 75 años de creación}

\author{
Faculty of Dentistry of the \\ National University of San \\ Marcos: 75 years of its creation
}

Carlos Alberto Arroyo Pérez 1,a

${ }^{1}$ Universidad Nacional Mayor de San Marcos, Facultad de Odontología. Lima, Perú.

a Magíster en Estomatología. Vicedecano Académico.

\section{Correspondencia:}

Carlos Alberto Arroyo Pérez

Correo electrónico: carroyop@unmsm.edu.pe

Universidad Nacional Mayor de San Marcos, Facultad de

Odontología. Calle Germán Amézaga 375. Lima 1, Perú.

Fecha de recepción: 06/11/18

Fecha de aceptación: 12/11/18
El 23 de julio del 2018 se cumplieron 150 años de enseñanza de la odontología en el Perú, la cual se inició en la Sección Dental de la Facultad de Medicina de la Universidad Nacional Mayor de San Marcos (UNMSM); sección que se separó e independizó de la Facultad de Medicina y hasta cierto grado de la universidad con la creación del Instituto de Odontología el 20 de junio de $1920{ }^{1}$. Sin embargo, debido a problemas al interior de este instituto, las autoridades decidieron clausurarla temporalmente y nuevamente cobijarla en el interior de la Universidad de San Marcos, aunque con una relativa independencia, adoptando el nombre de "Instituto Universitario de Odontología”, a partir de 1923. En octubre de 1930 la universidad fue cerrada, y el gobierno de ese entonces encargó a una comisión la elaboración y presentación de un proyecto de ley para la nueva estructuración de la UNMSM ${ }^{2}$.

Así nace la Escuela de Odontología, al amparo de la Facultad de Medicina, pero siempre con la aspiración de independizar la profesión para su desarrollo autónomo. Después de hechos importantes para conseguir el anhelado deseo, y luego de consolidar sus aspiraciones a nivel de la Facultad de Medicina y universidad; se presentó el proyecto de ley respectivo, al parlamento, por medio del cirujano dentista Dr. Leonardo Hidalgo Reyes, quien, por entonces, era diputado por Rioja. La propuesta le- gislativa fue aprobada y promulgada; y es así que mediante la Ley No 9838 del 29 de octubre de 1943, se crea la Facultad de Odontología de la UNMSM ${ }^{2}$. El 29 de octubre último nuestra facultad celebró los 75 años de aprobada la ley y su creación. Conocer este recuento histórico es importante porque representa el nacimiento de nuestra profesión en el Perú.

La trascendencia de la UNMSM en el Perú, se extiende mucho más allá del contexto de la educación universitaria, porque fue protagónica antes que el Perú fuera independiente, porque es arte, cultura, pensamientos políticos, ciencia, fe y todos los aspectos que perfilan el rostro de los países que emergen, y que San Marcos las engendró y las cultiva desde hace casi 500 años. De igual forma la trascendencia de la Facultad de Odontología de la UNMSM, para el Perú, no se limita a ser sólo la más antigua, es una mezquindad semántica afirmar ello, pues ella encarna en sí roles que van desde la histórica, pionera y noble aspiración de ser protectora de la salud bucal de un país hasta ser fuente invaluable e inagotable de inspiración para la creación de otras escuelas de odontología; desde tener una estructura misional que envuelve la generación de conocimiento nuevo, pertinente y autóctono, la formación del mejor recurso humano profesional y su responsable vinculación con la sociedad a donde se proyecta y extiende para inte- 
grarse a ella en busca de su bienestar, hasta su constante capacidad de evolución e innovación acorde a las nuevas demandas planteadas a la educación universitaria, expresadas en su proyecto educativo, la cual se desarrolla en una infraestructura óptima y equipamiento de tecnología avanzada.

Nuestra facultad se integra y fomenta el desarrollo en los nuevos escenarios para la educación superior universitaria, fruto de la promulgación de La Ley N. 30220 - Ley Universitaria; la que plantea como tema medular la exigencia en la calidad del servicio educativo que prestan las universidades, comprometiéndose a garantizar la mejor formación del estudiante, el impacto proactivo a la sociedad y el cumplimiento del fin público de la formación en las universidades; promoviendo el conocimiento, la formación integral de los futuros profesionales y el desarrollo social del país y haciendo que la mejora continua sea el sustento de nuestras buenas prácticas, promoviendo la excelencia y, como fruto de ello, tener respuestas pertinentes a las demandas y expectativas sociales del país ${ }^{3}$.

La Facultad de Odontología armoniza sus políticas de gestión con la Política de Aseguramiento de la Calidad de la Educación Superior Universitaria, reconociendo en ella, sus cuatro pilares: el licenciamiento, la acreditación, el fomento y los sistemas de información ${ }^{4}$, posibilitando nuestro aporte al licenciamiento de la universidad, lograda recientemente y comprometidos a alcanzar el nivel siguiente: la acreditación de nuestra carrera.

Han transcurridos 75 años, y desde ese entonces los hombres en nuestras aulas, cual valioso carbón, han cumplido con la digna misión de iluminar y abrigar los más nobles propósitos. Setenta y cinco años es un tiempo suficiente para volver la mirada atrás y apreciar el panorama de lo transcurrido, para mirar el pasado, para medir el presente, para planear el futuro, para ratificar o rectificar, para dar una prudente mirada y sincera reflexión sobre lo hecho, correcto o no. En estos 75 años transcurridos la universidad y nuestra facultad ha transitado por diversas vivencias; nace el año en que ocurrió el incendio de la Biblioteca Nacional y cuya reconstrucción fue un reto asumido por un ilustre sanmarquino, el historiador Jorge Basadre, el fin de la segunda guerra mundial, la consolidación de la soberanía sobre nuestras 200 millas marinas, el otorgamiento del derecho de sufragio a las mujeres, el golpe de estado de 1968 por el general Velasco Alvarado, la insania terrorista, el "autogolpe" de estado en el gobierno de Fujimori, el develamiento de la corrupción y retorno a la democracia 5, la promulgación de una nueva Ley Universitaria y la actual crisis moral por la que transita nuestro país. Y en este mar de sucesos nuestra facultad ha navegado, con los tripulantes más expertos: las personas que vivimos en ella y si está vigente aún, es porque ha demostrado tener la fortaleza que distingue a las personas que trascienden y que hacen posible que las cosas cambien. Notables académicos abundan en nuestra universidad y facultad, nuestros problemas no radican en la ausencia de personas inteligentes, nuestra reflexión debe ser: ¿al servicio de qué, está nuestra inteligencia? Y debemos reafirmar como siempre que San Marcos estará siempre al servicio de lo correcto, de la verdad, del respeto, del amor, de la libertad, de la justicia, de la tolerancia, de la equidad, de la paz y la honestidad.

Son actualmente muchas las carreras de odontología en nuestro país, pero sólo una resalta nítidamente entre ellas, una, no solo por su rol histórico, sino principalmente por el aporte ideológico primigenio a la enseñanza universitaria de la odontología y el liderazgo institucional evidenciado: la Facultad de Odontología de la UNMSM.

En alguna pared de los patios del pabellón nuevo y al pie de una escultura metálica que simboliza el escudo de nuestra facultad, hay una placa que fue colocada hace 20 años, cuando se cumplieron 130 años de la enseñanza de la Odontología en el Perú; que ha sido mudo testigo del tiempo transcurrido y que invitamos a visitar y leer en ella una verdad escrita, un proverbio persa que dice: "El viento de la adversidad nunca sopla en el reino de la sabiduría". Somos una facultad que dio nacimiento a la profesión odontológica y que ha cumplido 75 años, acompańando los 150 años de enseñanza de la odontología en el Perú y que pertenece a una universidad que va enrumbado a cumplir 500 años de existencia. Es tiempo suficiente para afirmar que ese proverbio persa es cierto, porque, aunque humanamente imperfectos, somos capaces de superar las adversidades que se presenten delante de nosotros y aún, tarea más gigantesca, superar las adversidades más difíciles de vencer, aquellas que nacen de nosotros mismos.

Nosotros, los que constituimos la comunidad odontológica sanmarquina, y que somos los cimientos vivos de nuestra facultad, declaramos estar de pie, firmes y presentes como ayer, hoy y siempre en estos 75 años transcurridos, con la mirada en el futuro de nuestra universidad y el compromiso de realizar el trabajo pendiente que Dios y la patria impone.

\section{Referencias bibliográficas}

1. Arrús J. Inicio de la enseñanza de la odontología en el Perú. Cultura, Ciencia y Tecnología. ASDOPEN-UNMSM [Internet]. Enero-Junio 2014 [citado 28 de Oct de 2018]; 5:3-8. Disponible en: http://asdopen.unmsm. edu.pe/files/Revista5-1.pdf.

2. Facultad de Odontología. Oficina de prensa e imagen institucional. Historia. Conoce la historia de la creación de la Facultad de Odontología [Internet] Lima: Universidad Nacional Mayor de San Marcos. [actualizado 2017; citado 28 octubre de 2018] Disponible en: http://odontologia.unmsm.edu.pe/historia/.

3. Dirección General de Educación Superior Universitaria - DIGESU Ministerio de Educación. Política de Aseguramiento de la Calidad de la Educación Superior Universitaria. Decreto Supremo N. ${ }^{\circ}$ 016-2015-MINEDU. [Internet] Disponible en: http://www.minedu.gob.pe/ reforma-universitaria/pdf/politica.pdf.

4. Superintendencia Nacional de Educación Superior Universitaria. El Modelo de Licenciamiento y su Implemen- 
tación en el Sistema Universitario Peruano. [Internet]. Lima: SUNEDU; noviembre 2015 [citado 28 octubre de 2018] Disponible en: http://www.untumbes.edu.pe/ paginas/informacion/oficinas/Calidad\%20Universitaria/ documentos/X5.\%20Mod_Lic_SUNEDU_Final.pdf.
5. Sechinense histórico. Para desarrollar los temas de Historia del Perú. [Internet]. [place unknown]: El Perú a partir del 1930 hasta la actualidad [citado 28 de octubre de 2018]. Disponible en: http://sechinensehistorico.blogspot.com/p/el-peru-partir-de-1930-hasta-la.html. 